\title{
La elección de Insulza en la OEA
}

\author{
Insulza's election in the OAS
}

\section{Ignacio Walker*}

Al cumplirse dos años de la elección de José Miguel Insulza como Secretario General de la Organización de los Estados Americanos, tal vez sea interesante preguntarse cómo se elige a la máxima autoridad de la OEA; qué tipos de coaliciones se forman y sobre la base de qué lógicas; cómo y a qué nivel se dan las negociaciones e interacciones, tanto a nivel de Jefes de Estado y Jefes de Gobierno (Caribe), como de Cancilleres y Cancillerías, y cuál es el rol de los medios de comunicación; qué es lo que está realmente en juego; cuál es el papel de los Estados Unidos -los críticos han considerado, históricamente, a la OEA como «el Ministerio de Colonias de los Yanquis» y de los demás países de la región, en las siempre complejas relaciones interamericanas. Lo que sigue es el relato que escribí recién concluida la elección de Insulza, en mayo de 2005. Tal vez convenga di- fundirlo no solo por el interés periodístico que pueda tener, sino también académico. Si bien transcurrido algún tiempo uno puede formarse otra percepción de las cosas, he preferido conservar el texto, sin modificación alguna.

«¿Y por qué no, José Miguel?», sugirió el canciller mexicano Luis Ernesto Derbez, refiriéndose a la próxima elección del Secretario General de la OEA. La pregunta fue formulada en el marco de la reunión del Asia Pacific Economic Forum (APEC), celebrada en Santiago de Chile el 20 de noviembre de 2004 y de la visita oficial del Presidente de México, Vicente Fox, en la reunión bilateral entre Chile y México que sostuvieron ambos Presidentes (Lagos y Fox) y a la que asistimos Derbez y yo, como Cancilleres.

Se trataba de la elección del Secretario General de la Organización de los

Presidente de la Corporación de Investigaciones Económicas para Latinoamérica (CIEPLAN). 
Estados Americanos (OEA) que, aunque no tenía fecha, era impostergable debido a que la organización estaba acéfala desde la renuncia del ex Presidente de Costa Rica, Miguel Ángel Rodríguez, en 2004, a raíz de acusaciones por supuestos casos de corrupción.

La verdad es que México y Canadá fueron los primeros y más decididos impulsores de la candidatura de José Miguel Insulza a dicho cargo. Su nombre había surgido en el tiempo de la elección de Miguel Ángel Rodríguez, pero por razones que no viene al caso señalar, todos decidieron finalmente apoyar la candidatura del costarricense.

La frase de Derbez tenía para mi una especial significación pues algunas semanas antes, en el marco de la inauguración de la Feria del Libro, que en 2004 estuvo dedicada a México y en una cena en el restaurant "Guernica», junto al propio José Miguel Insulza y a la ex canciller Soledad Alvear -quien dicho sea de paso había trabado cierta amistad con Derbez-, este me había insinuado privadamente la posibilidad de apoyar a Insulza, pese a que me había deslizado que él mismo podía ser el candidato y que lo estaba pensando.

Lo cierto es que nosotros no podíamos seguir dilatando la decisión sobre la posible candidatura de Insulza, en especial si se considera que Canadá, que había sido uno de los primeros en apoyarnos, daba señales de que había esperado demasiado tiempo un pronunciamiento de Chile al respecto. Quedamos en reunirnos con el Presidente
Lagos y el Ministro Insulza el viernes 26 de noviembre para considerar la opción y tomar una decisión. Sin embargo, por diversas razones debimos postergarla para el lunes 29 y finalmente para el miércoles 1 de diciembre. Hecho el análisis de rigor y preguntado el propio Insulza sobre su disposición personal a enfrentar tal elección, ese mismo día el Presidente Lagos resolvió impulsar la candidatura de Insulza, por la cual nos pusimos a trabajar desde ese mismo instante.

Lo primero que hice fue llamar al propio Derbez el jueves 2, es decir, al día siguiente de la reunión, pues me parecía de un mínimo de delicadeza comunicar la decisión a quien solo diez días antes, en la reunión ya mencionada realizada en Santiago, había sugerido la posibilidad de la candidatura de Insulza. «Me sacaste de la ducha», me dijo Derbez, al otro lado del teléfono. La verdad es que, por la diferencia de hora, en Ciudad de México eran las 7:30 horas y le expliqué la razón de mi llamado. «Te llamo, Luis Ernesto, y es la primera llamada que hago, porque te tengo una buena noticia: ayer nos hemos reunido con el Presidente Lagos y el Ministro Insulza, y el Presidente ha tomado la decisión de....». «A propósito», me dijo, interrumpiéndome, seguramente adivinando donde iban mis palabras y como si tuviera algo igualmente importante que comunicarme, "aprovecho de decirte que en el día de ayer el Presidente Fox me ha pedido que sea candidato a la Secretaría General de la OEA». 
Tras este intercambio se produjo el natural silencio en ambos lados, conscientes de que estábamos en un problema. Luego de algunos comentarios de rigor, no exentos de sentido del humor, quedamos en resolver la situación creada por esta "coincidencia», dejando el asunto en manos de ambos Presidentes, para que ellos tomaran la decisión definitiva sobre la materia. ("Qué lástima no haber tomado la decisión algunos días antes», me dije para mis adentros, pensando en ese viernes y lunes inmediatamente anteriores en que se postergó la reunión para decidir sobre el punto).

De inmediato me comuniqué con el Presidente Lagos y le dije lo que ocurría. Al día siguiente, viernes 3 de diciembre, Lagos se comunicó con Fox y quedaron en conversar el martes 7 en el Cuzco, durante una reunión a la que debíamos asistir, junto con otros mandatarios y cancilleres, para dar nacimiento a la Comunidad Sudamericana de Naciones.

Me pareció lógico no hacer nada entretanto, pues ambos presidentes habían quedado en actuar en conjunto y resolver el impasse entre ellos. De tal modo que no quedaba más que esperar hasta la reunión fijada para el martes 7 .

Nuestra sorpresa fue triple: el Presidente Fox no pudo llegar a la cita pues debió atender a una situación interna muy delicada, por lo que su ausencia era comprensible; el canciller Derbez había inscrito su propia candidatura a la OEA el lunes 6, es decir, el día antes de nuestra cita, lo que era francamente incomprensible y, en tercer lugar, había iniciado de inmediato su campaña haciendo algunas llamadas muy claves, que le significaron obtener nada menos que el voto de Canadá y algunos votos del Caribe, para lo cual había hablado, entre otros, con el Primer Ministro Patterson, de Jamaica. Obviamente, aprovecharía su presencia en Cuzco para tratar de conseguir algunos votos en Sudamérica, todo lo cuál nos causó una enorme extrañeza y molestia.

Así y todo, esa misma noche nos juntamos a cenar en un estupendo restaurante, el Presidente Lagos y yo, el propio canciller Luis Ernesto Derbez y el Vicecanciller de México, Miguel Hakim.

«Le debo una explicación», partió diciendo Derbez, dirigiéndose al Presidente Lagos y refiriéndose a la inscripción de su candidatura el día anterior.

Reconozco que hizo un gran despliegue de elocuencia y simpatía, y que seguramente pensó que no solo nos había convencido sino que, probablemente, podría contar con nuestro voto.

«Lo voy a pensar», dijo el Presidente Lagos, hacia el final de la cena y «le daremos a conocer nuestra decisión cuanto antes», añadió, culminando así una velada realmente muy grata, como siempre ocurría cuando se reúnen mexicanos y chilenos, que no solo tenemos una larga historia de amistad sino que habíamos creado estrechos vínculos bajo las presidencia de Vicente Fox-quien había encabezado la tran- 
sición a la democracia en México, recibiendo la banda presidencial de parte de Ernesto Zedillo- y Ricardo Lagos.

Para abreviar, Lagos estaba bastante contrariado. Se había roto el acuerdo a que había llegado tres días antes con el Presidente Fox y al día siguiente tomó dos decisiones: llamar a Fox para señalarle su extrañeza por esta decisión e impulsar la candidatura de Insulza. Esto último me lo comunicó cuando ya estábamos en la reunión del jueves 2 de diciembre de la Cumbre Sudamericana, mientras que la llamada a Fox la hizo en los minutos siguientes.

Le pedí autorización para empezar inmediatamente a conseguir algunos votos y fue así como a los 20 minutos le pasé un papel que decía algo así como «tenemos los dos primeros votos: Argentina y Brasil».

La verdad es que en ese breve lapso les pedí, por separado, una conversación al canciller Rafael Bielsa, de Argentina, con quien habíamos desarrollado una buena amistad, y al canciller Celso Amorim, de Brasil, que era un gran exponente del mítico Itamaraty (Cancillería brasileña), para solicitarles derechamente el apoyo para Insulza.

Actuábamos contra el tiempo y en los días siguientes me di cuenta de que Derbez y el propio Presidente Fox ya habían hecho algunos llamados a Presidentes y Cancilleres, lo que hacía la campaña bastante cuesta arriba. En fin, les expliqué a Bielsa y Amorim que si bien nos habíamos demorado en tomar una decisión en relación con la candidatura de Insulza, esta reunión, que nos convocaba precisamente para crear la Comunidad Sudamericana de Naciones coincidía muy bien con el lanzamiento de una candidatura sudamericana.

Tanto Brasil como Argentina nos habían adelantado su disposición a apoyar una eventual candidatura de Insulza, por lo que no estimaron necesario consultar a sus Presidentes. Eran dos votos muy valiosos y aunque seguíamos contra el tiempo, teníamos que aprovechar esa reunión para hacer algunos contactos y algunos llamados.

Pusimos en alerta a José Miguel Insulza en Santiago y a Cristián Barros, el Subsecretario de Relaciones Exteriores, quien habría de ser clave en reunir los votos del Caribe (no sé si hizo cuatro, cinco o seis viajes por los países del Caribe en las semanas y meses siguientes, pero fueron varios y muy intensos y productivos). Considerando que a esta Cumbre Sudamericana asistían los Presidentes y Cancilleres de Suriname y de Guyana, pensé que ambos países podrían llegar a jugar un papel clave en el Caribe. En Chile no tenemos mucha conciencia de que ambos pertenecen a nuestra región sudamericana, pues buena parte de sus actividades y relaciones tienen que ver con el Caribe y la CARICOM, organización regional que agrupa a los 14 países del Caribe -aunque en el último año la participación de Haití se encontraba temporalmente suspendida, a raíz del derrocamiento de Aristide. Lo cierto es que ambos países aparecían nada menos que como cofundadores y miembros de 
esta Comunidad Sudamericana en proceso de formación, por lo que desde todo punto de vista, pero particularmente en términos electorales, resultaban estratégicos para nuestros propios objetivos.

Fue así como de inmediato me puse en contacto con mis colegas Maria Levens, de Suriname, y Rudy Insanally, de Guyana, con los que terminaríamos trabando una estrecha amistad y complicidad, y agendé una reunión para esa misma tarde del 2 de diciembre en el Cuzco, con el Presidente Lagos. Una reunión de los tres presidentes y los tres cancilleres que, vista en retrospectiva, sería decisiva en el curso posterior de los hechos.

Esto último porque, en definitiva, Suriname y Guyana eran como una especie de puente entre América del Sur y el Caribe, y esa alianza habría se constituirse tal vez en la clave del éxito de la candidatura de Insulza, primero en el dramático empate a 17 votos del 11 de abril de 2005, entre Insulza y Derbez y finalmente, por razones que relataré más adelante, en el resonante triunfo del 2 de mayo, en el que obtendríamos 31 votos de los 34 Estados que forman la OEA.

Además, Suriname presidía la CARICOM y, sin saberlo entonces, tras casi 25 años de intentos frustrados, en febrero inaugurarían la sede de la organización nada menos que en Guyana, con la presencia de un solo invitado ajeno a la CARICOM: el Presidente de Chile, Ricardo Lagos. Otro momento clave de este proceso.
Las semanas siguientes a la reunión del Cuzco fueron tensas y confusas. Cada voto fue un verdadero parto. Por de pronto, había surgido una tercera candidatura, impulsada por Estados Unidos y algunos países de Centroamérica: la del ex Presidente de El Salvador, Francisco Flores. Centroamérica, con toda legitimidad, quería recuperarse del impacto de la renuncia de Miguel Ángel Rodríguez, acusado, como se ha dicho, de corrupción, y reclamaba una especie de mejor derecho para designar al sucesor, para lo cual aspiraba a un consenso de los países del Sistema de Integración Centro Americano (SICA) y luego de la región.

Lo cierto es que ni lo uno ni lo otro fue posible. Por un lado, Belice -que desde un comienzo estuvo con México, lo que es perfectamente natural dada su vecindad con el país del norte- se restó a ese consenso centroamericano y también lo hicieron Honduras -seguramente por los conflictos limítrofes que había tenido con El Salvador-y Panamá que, según relataremos más adelante, resultaría clave en el triunfo de Insulza. A pesar de todo, el discurso de todos los países centroamericanos, incluida la República Dominicana-que a pesar de pertenecer al Caribe es parte del SICA- era que aspiraban a un candidato de consenso centroamericano (poco después, en forma muy hábil, el canciller Derbez los convencería de que el consenso debía ser «mesoamericano», con lo cual incorporaba a México).

Como no había tiempo que perder, 
le sugerí al Presidente Lagos que yo mismo debía hacer una rápida gira por Centroamérica para marcar presencia y exponer las razones de nuestra candidatura, conscientes como estábamos de que teníamos pocas posibilidades de captar votos y que a lo más podíamos aspirar a algún «segundo voto», pensando en la posibilidad de una segunda vuelta entre los tres candidatos en competencia: Francisco Flores (El Salvador), Luis Ernesto Derbez (México) y José Miguel Insulza (Chile).

Partí de inmediato en un avión Citation de la FACH y recorrí seis países centroamericanos en cinco días, en lo que llegó a ser una verdadera maratón; entretanto, Cristián Barros hacía su primera o segunda vuelta por el Caribe. Visité Guatemala, Honduras, Costa Rica, Nicaragua, Panamá y República Dominicana. Por razones obvias, de mínima deferencia o delicadeza, no fui a El Salvador ni a México.

En lo positivo, pude constatar el gran estado de las relaciones bilaterales que existía (y existe) con todos los países mencionados, la amistad histórica que ha existido con Centroamérica y, por qué no decirlo, la admiración que tienen por Chile. Sin embargo, de votos ni hablar (incluso el Presidente Ricardo Maduro nos adelantó, ante la misma pregunta que les formulé a todos los demás, que su segunda opción era Derbez). Debo confesar que, como ocurre con toda elección, llegué a agradecer a los países que nos daban a conocer francamente su opción, aunque fuese contraria a nuestras pretensiones, pues lo peor que puede ocurrirle a un candidato es quedar en la duda, o que le expresen derechamente el apoyo y luego hagan otra cosa, como ocurriría con dos de los catorce países del Caribe en la dramática elección del 11 de abril.

Por nuestra parte, mostramos mucha comprensión por la situación electoral, en la búsqueda de un "consenso centroamericano», pero aunque regresáramos a Chile con las manos vacías, lo importante fue el acto de presencia. La verdad es que, con la ayuda de Carlos Rubio, nuestro Embajador en República Dominicana, conseguimos al menos el segundo voto de ese país del Caribe, lo que resultaría decisivo en la tensa y dramática elección del 11 de abril.

La campaña siguió adelante en Sudamérica y fue así como conseguimos los votos de Ecuador, Venezuela y Uruguay, que se sumaron a una buena masa crítica sudamericana junto a Argentina, Brasil y Chile (los países del $\mathrm{ABC}$ ). Ninguno de ellos fue fácil. Ecuador era objeto de fuerte presión por parte de los Estados Unidos, al igual que la mayoría de los países de la región. Finalmente, ante la estrecha y estratégica relación con Chile, el canciller Patricio Zuquilanda nos dio su apoyo aunque nos pidió que no lo hiciéramos público. Solo algunas semanas después y en el contexto de una gira pactada de Insulza a Quito, pudimos dar a conocer el apoyo de Ecuador.

El voto de Venezuela lo consiguió personalmente el Presidente Lagos con 
el Presidente Hugo Chávez en la Cumbre del Mercosur de Belo Horizonte. Chávez, sin embargo, nos pidió que Insulza lo visitara en Caracas para poder explicitar y publicitar el apoyo de Venezuela, lo que se hizo. Desde ese momento, el apoyo de Chávez se convertiría en el principal argumento (o excusa) de Estados Unidos para no apoyar a Insulza, causando una similar inquietud en otros países de la región -en la elección siempre estuvo rondando la idea de que no se podía llegar a ser Secretario General de la OEA sin el apoyo de Estados Unidos. Finalmente, el apoyo de Uruguay solo fue posible a partir del 1 de marzo de 2005 con la llegada al poder del Presidente Tabaré Vásquez, lo que nos imponía la obligación de no realizar la elección antes de esa fecha. En algún momento Derbez insinuó la posibilidad de hacerla antes pues, al parecer, contaba con el apoyo del Presidente Jorge Battle.

Este apoyo sudamericano fue interpretado crecientemente por Estados Unidos como un apoyo de la «nueva izquierda» que surgía en la región (Lagos, Lula, Chávez, Kirchner y Tabaré Vásquez), cuyo aspecto más preocupante era Hugo Chávez. También implicaba atribuirle a la campaña una dimensión «ideológica», supuestamente con algún sesgo anti-Estados Unidos y, a la postre, con un tinte de confrontación norte-sur.

Por supuesto, todas estas imágenes y fantasmas, que fueron acrecentándose en las semanas siguientes, eran totalmente ajenas a nuestras propias inten- ciones, pero era difícil ir contra las "percepciones» que comenzaban a instalarse en distintos actores de la región, alimentadas por algunos altos personeros del Departamento de Estado del país del Norte.

En cuanto al resto de los países sudamericanos -llegaríamos a tener el apoyo de 9 de los 12- la situación era la siguiente: sabíamos que nunca íbamos a contar con el apoyo de Bolivia, por razones obvias. Entendíamos que Colombia estaba muy ligado y comprometido con Estados Unidos por el Plan Colombia, que significaba al país un apoyo anual de más de más de mil millones de dólares, sin perjuicio de las excelentes relaciones bilaterales entre nuestros dos países y muy particularmente entre el Presidente Alvaro Uribe y Ricardo Lagos. Paraguay tenía sus propias pretensiones de elegir como Secretario General Adjunto de la OEA a la canciller Leyla Rachid, lo que a nuestro juicio no tenía mucho asidero, especialmente porque era impensable que se eligieran un Secretario General y un Secretario General Adjunto, ambos de Sudamérica, aunque su aspiración era enteramente respetable. Finalmente, aunque no descartábamos a priori un eventual apoyo del Perú, la controversia posterior por una supuesta entrega de armas de Chile al Ecuador a comienzos de 1995, le dio al gobierno del Presidente Alejandro Toledo el argumento -o supuesto, o pretexto, o lo que fuere- perfecto para no apoyar la candidatura chilena.

Finalmente, las elecciones fueron 
fijadas para el lunes 11 de abril de 2005 en Washington D.C., con una grata noticia para Chile: el 31 de marzo, los países de la CARICOM anunciaban que la overwhelming majority de sus miembros, en la búsqueda que dichos países habían hecho de un "consenso» del Caribe, había decidido apoyar a Chile. Esta fue una noticia muy publicitada que nos hacía creer que, con la sola excepción de Belice y San Vicente y las Granadinas, que desde un principio habían decidido apoyar a México, podíamos contar con 11 de los 13 países del Caribe, de un total de 14 (recordemos que la participación de Haití estaba suspendida).

Ya algunos días o semanas antes, Rudy Insanally, un avezado diplomático de Guyana, con quien, como he dicho, hicimos buena amistad, me "sopló» una frase que habría de hacerse famosa entre nosotros y que reflejaba, literalmente, los vientos que soplaban en el Caribe en relación con la candidatura chilena: «the wind is blowing to your side», me dijo, lo que hacía subir nuestras expectativas del ansiado triunfo. Clave había sido la presencia de Lagos en la inauguración de la sede de la CARICOM, en Guyana, y clave había sido también nuestro apoyo a la candidatura oficial de dicha organización a la Secretaría General Adjunta, de Albert Ramdim, de Suriname (quien a la postre resultaría elegido por 19 votos a favor y 14 en contra en la Asamblea General de la OEA celebrada en Fort Lauderdale, Estados Unidos, en 2005). En los meses anteriores, Cristián
Barros y el propio José Miguel Insulza habían desplegado una intensa actividad en el Caribe, incluso asistiendo a la crucial reunión en Georgetown, Guyana, en la que expusieron los tres candidatos. De esa reunión salieron con 7 votos seguros, y otros probables, que habrían de ser decisivos a la hora del triunfo.

En definitiva, se logró una estrecha relación entre Sudamérica y el Caribe $y$, con algunas excepciones que relataremos a continuación, sumadas a las ya mencionadas de Belice y San Vicente y las Granadinas, el Caribe habría de cumplir su palabra con mucho aplomo y coherencia. Me inclino a pensar que una de las razones de las tensiones que se sucedieron con el candidato mexicano, Luis Ernesto Derbez, se relacionan precisamente con el hecho de que Chile lograra tan contundente apoyo en el Caribe, en el que por diversas razones históricas y de todo tipo, México había tenido gran influencia.

Lo cierto es que en las elecciones del lunes 11 de abril obtuvimos un total de 17 votos, incluidos 6 votos de Sudamérica (Argentina, Brasil, Chile, Ecuador, Venezuela y Uruguay) y 11 votos del Caribe (todos los de la CARICOM con la excepción de Belice, San Vicente y Bahamas, más el de República Dominicana, que nos había comprometido su segundo voto para el caso de que no prosperara la candidatura del ex Presidente Flores).

Esto último fue precisamente lo que ocurrió el viernes 8 de abril, a tres días de la elección. Conscientes de que la 
candidatura salvadoreña no había podido conseguir un solo voto en el Caribe y que los propios centroamericanos tenían serias dudas sobre su candidatura, Estados Unidos tomó la decisión de quitarle el apoyo a Flores y apoyar derechamente a Derbez, con tal de evitar el triunfo de Chile, que parecía como bastante inminente (más que oposición a Chile y a Insulza, lo que descolocaba a incomodaba al extremo a Estados Unidos era el apoyo de Chávez y la posibilidad de aparecer como derrotados por el líder venezolano).

La noticia de la bajada de Flores fue como un "tsunami» para nosotros. Nos sentíamos muy cómodos con los 19 votos que creíamos tener (incluyendo los de Haití y Bahamas), frente a los siete $\mathrm{u}$ ocho que podían tener, respectivamente, Flores y Derbez (no teníamos claro cuál de ellos pudiera tener un voto más o un voto menos). De hecho, en Roma, en el funeral del Papa Juan Pablo II, precisamente ese viernes 8 de abril, ocasión en la que me tocó encabezar la delegación chilena, conversé con los Presidentes Miguel Torrijos, de Panamá, Ricardo Maduro de Honduras y Oscar Berger de Guatemala, los que habían concordado en que, si en la primera vuelta la votación era, digamos 17 para Insulza y 9 y 8 para cualesquiera de los candidatos Derbez o Flores, ellos mismos -sobre todo Panamá, con el beneplácito de Honduras y Guatemala- solicitarían el consenso para Insulza.

En ese contexto, la bajada de Flo- res y la activísima participación de Estados Unidos para conseguir el traslado de sus votos a Derbez -lo que consiguió, con la sola excepción de República Dominicana, por las razones ya indicadas-, nos colocó en un escenario completamente nuevo a 48 horas de la elección.

Ante este verdadero terremoto que veíamos venir, encontrándome yo en Roma e Insulza y Barros en Washington D.C., decidimos hacer un comunicado de la Cancillería el día sábado 9 para mostrar una fuerte imagen de triunfo y tratar de mantener los 19 votos que creíamos tener y que resultaron ser 17 por la situación ya explicada de Haití y Bahamas. El día domingo 10, a 24 horas de la elección, cometí un error que me fue cobrado sistemáticamente en los días siguientes al dramático empate del 11 de abril, en cuanto a que prácticamente di por hecho que teníamos los votos para ganar.

Reconozco mi exceso de optimismo y entusiasmo, pero señalo al menos como atenuante que teníamos que mostrar una clara y decidida imagen de triunfo para que no se nos «desgranara el choclo» ante la fuerte arremetida de Estados Unidos y México, con el apoyo de Norteamérica y Centroamérica, más algunos países del Caribe y Sudamérica.

Sigo pensando que fue heroico resistir cinco elecciones sucesivas en ese intenso y dramático lunes 11 de abril en pleno Washington D.C., en medio de las presiones más increíbles de parte de los Estados Unidos (los países «pre- 
sionados» nos contaban en detalle el tipo de presiones e «incentivos» que recibían, por ejemplo, que algunos días antes de la elección, Estados Unidos ofreció a los países del Caribe -lo que se hizo público por lo demás- crear un fondo de desarrollo de 20 millones de dólares). El resultado 17-17 entre Derbez e Insulza no era apto para cardíacos y lo cierto es que tendríamos que definir una nueva estrategia para el lunes 2 de mayo, fijada como nueva fecha de la elección.

La verdad es que en la mañana de esa votación hicimos un último esfuerzo por lograr algún tipo de consenso, en el que el papel de Estados Unidos resultaba bastante decisivo. Sin embargo, los ánimos estaban muy caldeados y la polarización electoral era una realidad. Recuerdo que ante mi firme defensa de un consenso en torno a Insulza, negándonos a cualquier otra posibilidad, el encargado para América Latina del Departamento de Estado de Estados Unidos, Roger Noriega, me dijo con verdadera indignación, estando los tres solos con el embajador ante la OEA, John Maisto, "could we have some $f . .$. respect from you»? La verdad es que me pedía una declaración inaceptable de parte nuestra en torno al Perú -el tema de las ventas de armas a Ecuador estaba al rojo vivo. En todo caso, reaccionó rápido y me pidió excusas dos o tres veces por sus palabras groseras, que en todo caso demostraban lo caldeados que estaban los ánimos (Maisto ayudó a distender la situación).
Tras el quíntuple y dramático empate a 17 votos y ante la imposibilidad de conseguir un consenso, regresé a Chile el mismo lunes 11 de abril y enfrenté a la prensa y a los que me acusaban de excesivo optimismo (que en parte tenían razón). Lo cierto es que en Chile estábamos cansados de «triunfos morales» y que el empate tenía sabor a derrota (entre otras cosas, insisto, por el exceso de optimismo que yo mismo había transmitido). Mi preocupación era otra: no quería exponer al Presidente Lagos a una derrota, y así se lo hice ver, aunque nuestra insistencia en esta candidatura era obvia: se nos había acusado repetidamente de estar aislados en la región; de que éramos el «mejor alumno» del barrio pero no el «mejor compañero», entre otras cosas que estaban instaladas en el ambiente. Un triunfo en la OEA tiraría por la borda toda esa imagen que existía respecto de nosotros en la región y brindaría al Presidente Lagos -y a la política exterior chilena- un resonante triunfo en el último año de su mandato. La cuestión se había puesto al rojo vivo y teníamos que definir una estrategia para la nueva elección fijada para el lunes 2 de mayo.

Tras evaluar la situación, nos pusimos de inmediato a trabajar. Con Cristián Barros, Carlos Portales, Director de Política Exterior, Pedro Oyarce, Director de Política Multilateral y el propio candidato, José Miguel Insulza, comenzamos a diseñar una estrategia para la segunda vuelta. Periódicamente nos reunimos con el Presidente La- 
gos, quien asumió un compromiso directo y efectivo en la campaña, ya fuere viajando a determinados países, como lo había hecho en la primera vuelta -muy particularmente exitosa había sido su gira por Guyana, Trinidad y Tabago, Barbados y Granada, además del encuentro con Jefes de Estado en diversas cumbres. También nos mantuvimos en contacto permanente con Esteban Tomic, nuestro Embajador en la OEA -el que, a su vez, se relacionaba con Andrés Bianchi, Embajador en Washington D.C. y Heraldo Muñoz, Embajador en Naciones Unidas- y, en general, nuestros embajadores en la región, incluyendo muy particularmente a Alfonso Silva, Embajador en Jamaica para casi todo el Caribe. Todos trabajaron con «la camiseta puesta», con mucha dedicación y mística.

Otro de nuestros capitales fue la gran unidad interna como país, ya que tanto el Gobierno como la oposición cerraron filas en torno a Insulza. Es más, no hubo una sola voz disidente en Chile, lo que contrastaba visiblemente con las fuertes críticas que recibieron internamente tanto el ex Presidente Flores, en El Salvador, como Luis Ernesto Derbez, en México. De hecho, el senador Hernán Larraín, como Presidente del Senado, acompañó a Insulza cuando este expuso ante el Consejo General de la OEA en Washington D.C., lo que se hizo notar. Por su parte, Pablo Longueira llamó a Roger Noriega, asistente para América Latina del Departamento de Estado, a petición mía, encontrándonos ambos en Roma para el inolvidable y memorable funeral del Papa Juan Pablo II. Sergio Romero hizo lo suyo y, así, distintos personeros de la oposición se sumaron activa y entusiastamente a la campaña. Tras el triunfo del 2 de mayo, medio en serio medio en broma los personeros de oposición dijeron, primero en privado y luego públicamente, que harían cualquier cosa por "deshacerse» de Insulza quien, además de su notable capacidad política en el frente interno, siempre había estado latente como una de las mejores cartas presidenciales de la Concertación...

La semana siguiente al quíntuple empate los dardos se dirigieron contra mí. Derechamente, al hacer mi primera declaración pública dije "Asumo personalmente la responsabilidad por este resultado», aunque aclaré dos cosas: que era un empate y no una derrota-aunque reconozco que con sabor a derrota pues yo mismo había contribuido a generar claras expectativas de triunfo. En segundo lugar, relacionado con esto último, me pregunté: "¿Qué jefe de campaña no confía en el éxito de su candidato?».

Algo salvé con esas declaraciones pero me dieron duro distintos sectores tanto de gobierno como de oposición. Particularmente ingrata fue mi reunión con la bancada de senadores DC, los que casi sin excepción me sugirieron que había que bajar a Insulza y que debía buscarse una solución "digna», entiéndase, de consenso en la región sobre la base de un tercer candidato.

La verdad es que yo tenía una fe ciega en la candidatura de Insulza. Pri- 
mero, porque era un candidato de excepción, que podría contribuir a revertir la tendencia declinante da la OEA dotando al organismo hemisférico de un nuevo liderazgo político en momentos en que, una vez más, la región se debatía en la ingobernabilidad democrática, los Estados fallidos, los problemas de seguridad y desarrollo; segundo, porque teníamos el apoyo decidido del Presidente Lagos, cuyo prestigio en la región era muy grande; tercero, porque como país gozábamos de una alta respetabilidad y éramos señalados una y otra vez como "modelo» a seguir (cuestión que tratábamos de evitar porque alimentaba la idea de una cierta arrogancia) y cuarto porque, al constatar la percepción de aislamiento en la región -subrayo lo de percepción porque sigo considerando que no corresponde a la realidad-y frente a los tres aspectos antes mencionados, esta era una clara oportunidad para demostrar que no estábamos aislados y que, antes bien, podíamos ejercer un liderazgo sobrio pero efectivo, construyendo alianzas alrededor de una visión o programa que tuvimos la ocasión de exponer por todos lados en torno a los temas de seguridad, desarrollo y democracia.

Volviendo a la campaña y la estrategia para la segunda vuelta, mi primera misión consistió en llamar uno por uno a los 16 países que habían votado por nosotros. En menos de cuatro o cinco días logré comunicarme con todos los cancilleres, de los que recibí una doble señal: que se mantenían fir- mes ( «we stand firm», me dijo nuestro amigo Rudy Insanally, de Guyana) y que estaban entusiasmados por el resultado. Decían que este era un gran logro y que, a fin de cuentas, era como una cuestión de dignidad el haber resistido tantas presiones. Su sugerencia era que siguiéramos adelante.

Mi sorpresa fue Bahamas, ya que descubrí que no había votado por nosotros.

«¿Por qué pensaste que votaríamos por ustedes?", me dijo el Canciller Fred Mitchell, de Bahamas, así de claro y para mi total sorpresa.

«¿A qué te refieres?», le dije, entre sorprendido y enojado, "tu Primer Ministro llamó el viernes 8 de abril a mi Presidente para confirmarle que Bahamas votaría por Insulza».

«Ah», me respondió. «Debe haber algún malentendido, porque mi Primer Ministro me dijo que yo tomara la decisión y, tras algunos análisis de nuestra situación financiera interna, decidí que estaba en nuestro interés apoyar a Derbez».

Debo reconocer que preferí este tono franco y abierto al compararlo con otras situaciones bastante más confusas y desconcertantes.

Una de ellas fue la de Haití, país que nos había reiterado una y otra vez que votaría por nosotros. Me lo dijo el Primer Ministro Latortue en mi visita a Haití y me lo confirmó él mismo en el funeral del Papa Juan Pablo II, en Roma, tres días antes de la elección. Posteriormente y ante la duda que teníamos, pedí hablar personalmente con 
el Canciller Abrams a escasos minutos de la elección y me confirmó, con toda seguridad, que votaría por nosotros. En fin, reconozco que mi amigo el canciller Carlos Morales, de República Dominicana, fue mucho más aterrizado y realista: siempre me dijo que por ningún motivo Haití votaría por nosotros pues terminaría por alinearse con Estados Unidos (entiéndase, la candidatura mexicana). Lo cierto es que, según supimos después, fue el propio Presidente de Haití, Bonifaz Alexander, el que, bajo una fuerte presión de Estados Unidos -como había ocurrido con varios otros países- ordenó al Canciller Abrams votar por Derbez (de hecho, me dediqué a observar a Abrams mientras emitía el sufragio y parecía un niño colegial, con el voto muy escondido o protegido, como haciendo una maldad).

Ahí estaban los votos que nos faltaban. Nosotros estábamos seguros de contar con 19 votos, porque los Primeros Ministros de Bahamas y Haití nos lo habían asegurado y reconfirmado, pero lo cierto es que las cosas se dieron de otra manera.

Tras conversar personalmente y por vía telefónica con los 16 cancilleres y constatar que estos dos eran los votos que nos habían fallado, vino la otra parte de la estrategia para la segunda vuelta: la gira sudamericana con el Presidente Lagos.

Inicialmente teníamos un compromiso de visitar Ecuador y Venezuela. Sin embargo, los hechos acaecidos en Ecuador, con la remoción del Presidente
Lucio Gutiérrez, nos hicieron cancelar la visita. Nuestra próxima preocupación era evitar que fuese mal interpretada nuestra visita a Venezuela, que era la fijación de Estados Unidos. Aparecer como «el candidato de Chávez» nos acarreó una serie de problemas y teníamos que evitar a toda costa aparecer con una única visita a Venezuela entre la primera y la segunda vuelta porque serviría para todo tipo de especulaciones. Por otro lado, teníamos normales relaciones diplomáticas con la República Bolivariana de Venezuela y de hecho nos había ayudado con algunos países en el Caribe, de lo que siempre estaremos reconocidos, así es que decidimos mantener a firme la visita oficial. El Presidente Lagos, no obstante, con gran astucia y sagacidad, decidió comenzar la gira por Brasil, que había sido muy importante en la primera vuelta y que, según nuestras estimaciones, podría serlo en la segunda especialmente en términos de tratar de convencer a Paraguay de apoyar a Insulza. Junto con ello, decidimos incluir una visita al Presidente Álvaro Uribe de Colombia, con quien realmente nos llevábamos muy bien. Así, por lo demás, lograríamos un buen equilibrio en términos de las imágenes y percepciones en relación con el tema de Venezuela.

Para abreviar la historia, la gira sudamericana fue todo un éxito. Ya en Brasil habíamos logrado el apoyo público de Paraguay, lo que ayudaba a inclinar la balanza en nuestro favor luego del dramático empate en la primera vuelta, además de un apoyo ex- 
plícito y total de parte del Presidente Lula.

La gira a Venezuela fue muy exitosa y nos atrevimos a pedirle al Presidente Chávez que por favor bajara la intensidad de su discurso anti-Estados Unidos, la que era desde todo punto de vista inconveniente. Finalmente, la visita a Colombia fue también muy exitosa en un doble sentido: por el agrado de reunirnos en su propia casa con el Presidente Uribe y la Canciller Carolina Barco, lo que siempre es reconfortante pues habíamos trabado cierta amistad con ambos, acompañados de un «ajiaco» inolvidable (muy casero y muy sabroso) y, en segundo lugar, por habernos reunido privadamente con nuestro amigo el Canciller y Vicepresidente de la República de Panamá, Samuel Lewis, quien viajó especialmente a Colombia para reunirse con nosotros.

Esto último requiere una nota aparte porque habría de ser clave en el triunfo posterior. Una hora antes de la elección del 11 de abril, Lewis nos había transmitido a Insulza y a mí, a nombre del Presidente Martín Torrijos, la decisión del presidente panameño de votar por Derbez, lo que lamentamos pero agradecimos por la franqueza que ello implicaba. La verdad es que el canciller panameño fue más allá y nos contó que, para el Presidente Torrijos -hijo del mítico Omar Torrijos y muy vinculado él mismo a la socialdemocracia internacional- esta había sido una de las decisiones más difíciles de su mandato, dada la gran amistad y cercanía con Chile y con el Presidente Lagos. El hecho es que, tras el empate del 11 de abril, Lewis recibió instrucciones del Presidente Torrijos de quedarse en Washington D.C. para explorar con Estados Unidos la posibilidad de un consenso en torno a Insulza. Efectivamente el canciller panameño se entrevistó con la propia Condoleezza Rice y empezó a trabajar en los días y semanas siguientes en torno a la idea de un consenso para Insulza, permaneciendo él y yo en permanente contacto (casi a diario, diría yo).

El panorama era pues bastante alentador, aunque queríamos evitar toda imagen triunfalista. Esta vez me quedé rigurosamente callado y nuestras declaraciones eran sobre las «razonables expectativas» de éxito y todas esas cosas que se dicen en situaciones como esa. Por un lado, teníamos en forma pública el voto de Paraguay y, por otro lado, teníamos a Panamá -ambos habían apoyado a Derbez en la primera vuelta- trabajando por un consenso para Insulza, lo que sin duda era auspicioso.

Al final, fue clave la posición de Estados Unidos en el resultado final de 31 votos a favor sobre un total de 34, con la sola excepción de Bolivia, Perú y México. Lo anterior, por dos razones fundamentales: en primer lugar, porque Estados Unidos no quería y no podía enfrentar una tercera derrota; la primera tras haber bajado a su candidato, Francisco Flores, la segunda con no haber ganado con su candidato, Luis Ernesto Derbez y, la tercera, ante la eventualidad de un triunfo de Insulza en la segunda vuelta, todo lo cual aparecería 
como una evidente derrota para el país del norte.

Lo segunda razón fue, a mi entender, una cuestión mucho más estratégica y se relacionaba con la propia Condoleezza Rice, una persona de gran inteligencia y talento político y diplomático. En el fondo, Edtados Unidos empezaba a darse cuenta de que, más que aislar a Venezuela y Chávez -que a esas alturas era como la única preocupación real de Estados Unidos en la región- era mejor intentar un trabajo desde Sudamérica y para ello, los Presidentes Lula y Lagos, ambos con una imagen de fuerzas progresistas y un reconocido prestigio en la región, podían llegar a constituirse en actores claves en la región.

En mi primera visita a Washington D.C., para entrevistarme con la Secretaria de Estado, algo de esto habíamos discutido. "Hay que evitar visiones simplistas en torno a la región», le dije, refiriéndome claramente a Venezuela, en favor de un constructive engagement en relación con dicho país. Estas mismas palabras fueron ampliamente publicitadas a partir de una charla que di al día siguiente en el Inter American Dialogue, con historia de portada en la prensa venezolana y la protesta formal de Roger Noriega y Thomas Shannon, del Consejo de Seguridad Nacional.

El hecho es que, por esas cosas del destino, la Secretaria Rice asistió a la Cumbre sobre las Democracias que se realizó en Santiago el jueves 28 y viernes 29 de abril, a escasos días de la votación en la OEA y el primero de esos días tuvimos la oportunidad de sostener una larga, muy amena y fructífera conversación junto al Presidente Lagos. Fue una gran «performance» del Presidente Lagos, en un momento muy crítico de la elección de la OEA. Sentí que su mensaje estaba llegando muy profundamente a la Secretaria Rice la que, como sabemos, no es muy experta en América Latina. Sin embargo, creo que la conversación sirvió para mostrar las complejidades y sutilezas de una región que nunca ha sido muy comprendida por la política exterior estadounidense. Ella hizo preguntas y comentarios muy precisos, agudos y atingentes, dejó hablar a Lagos y tuve la sensación de que estaba cerca de pasarse al consenso en torno a Insulza.

Mi sospecha se transformó en certeza cuando, muy delicadamente, ella le pidió a Lagos quedarse a solas con él por unos minutos.

«Ya está», pensé para mis adentros, " este es el típico amarre final. Estados Unidos se suma al consenso».

No me aguanté más y en la recepción de la noche le pregunté al Presidente Lagos por su conversación privada con Rice y me confirmó que estábamos muy cerca del apoyo de Estados Unidos, lo que me dio una gran alegría. Siempre habíamos apostado a un consenso en torno a Insulza y estábamos a punto de lograrlo, con la propia Secretaria Rice de por medio.

Quedaba, sin embargo, una última cuestión que no era menor y que había que enfrentar con especial delicadeza: qué hacer con Luis Ernesto Derbez. 
Lo cierto es que este llegó a Santiago a primera hora del viernes 29 de abril y su primera entrevista fue con la Secretaria Rice, ocasión en que, seguramente, ella le comunicó el estado de las conversaciones y la necesidad de buscar un consenso en el sentido que se ha indicado. A eso de las 10 de la mañana entraron a la reunión en el Hotel Hyatt los Cancilleres de Canadá, Paraguay, Colombia y El Salvador, estimando nosotros que el humo blanco era cuestión de minutos.

Cual no fue nuestra sorpresa con Insulza cuando nos invitan a pasar a la reunión, como a las 11:30 y, según nos dimos cuenta, la cosa no estaba tan madura como pensábamos.

La Secretaria Rice introdujo la reunión, tensa y decisiva, con palabras que no se me van a olvidar y que demuestran su gran sagacidad y finura: "this is my room -dijo- but it is not my meeting", como diciendo "ustedes tendrán que ponerse de acuerdo y yo estoy aquí nada más que para facilitar las cosas», procediendo a dar la palabra a Derbez y a los demás.

«Nos bajamos los dos, José Miguel, ¿qué te parece?», fueron las palabras directas y desconcertantes de Derbez.

Inmediatamente tomamos la palabra Insulza y yo y nos negamos a dicha posibilidad, entre otras cosas porque ya sabíamos que teníamos un par de votos adicionales, insistiendo en que íbamos a la elección sí o sí. Por mi parte, todo esto en inglés y en medio de un tenso silencio, le recordé a Derbez que él había sido uno de los primeros en apoyarnos: «¿Por qué no José Miguel?» $¿$ Te acuerdas? lo dijiste el 21 de noviembre en la reunión que sostuvimos con nuestros dos Presidentes, en el marco de la reunión del APEC».

Dirigiéndome a nuestro amigo el Canciller de Canadá, Pierre Pettigrew, que incluso sonaba como una posibilidad de consenso en el supuesto de que Derbez e Insulza se bajaran -escenario que, con toda franqueza, nunca consideramos-, le dije: "¿Recuerdas Pierre que tu país fue prácticamente el primero en apoyar la posibilidad de una candidatura de Insulza?». La verdad es que Canadá se había cansado de esperarnos ante nuestra demora en decidirnos por la candidatura de Insulza.

De reojo yo miraba a la Secretaria Rice y notaba que había aquí un dato nuevo que ella no manejaba y tal vez lo mismo sucedía con los demás, y era que México y Canadá habían sido los primeros efectivamente en manifestar su predilección por Insulza.

«Muy bien, dijo Derbez, para facilitar las cosas y en aras de la unidad de la región y de la OEA, entonces declino mi candidatura»

Yo no cabía en mí, aunque con Insulza no hicimos ningún gesto de triunfo. Muy por el contrario, reconocimos este gesto muy sinceramente, en todo lo que ello significaba, y nos dispusimos a bajar juntos a dar la conferencia de prensa para hacer el anuncio, no sin antes darle un telefonazo al Presidente Lagos para darle la noticia.

Nunca he visto tantos periodistas como en el primer piso del Hotel 
Hyatt. Con transmisión en vivo de los distintos canales de televisión, incluido CNN en español, Carolina Barco, la canciller de Colombia, con mucha dignidad y aplomo, y en la presencia de Insulza y Derbez y los Cancilleres de Panamá, Paraguay, El Salvador y Chile, comunicó que se había producido un consenso en torno a Insulza, y agradeció de paso el gesto de Derbez. Acto seguido, Insulza leyó una declaración pública, que habíamos estado preparando durante toda la noche anterior bajo la batuta de Carlos Portales.

Un proceso que había comenzado el 1 de diciembre de 2004 con la decisión de los presidentes Lagos y Fox, de impulsar las candidaturas de Insulza y Derbez, respectivamente, a la Secretaría General de la OEA, culminaba el lunes 2 de mayo de 2005, tres días después de este encuentro en Santiago, con la elección de José Miguel Insulza por 31 votos sobre un total de 34 .

La reunión de Washington D.C. fue meramente ratificatoria de un consenso que, aunque no unánime, tiró por la borda, así lo espero, la falsa percepción de que estábamos aislados en la región y de que éramos el mejor alumno del barrio pero no el mejor compañero.

El cariño fue grande y la alegría también. 